América sin Nombre, n. ${ }^{\circ} 21$ (2016): 21-37

DOI: 10.14198/AMESN.2016.21.01

ISSN: 1577.3442 / eISSN: 1989-9831

Fecha de recepción: 04/07/2016

Fecha de aceptación: 01/11/2016
Puede citar este artículo como:

Asenjo, Julio Alonso. «Teatro breve escolar virreinal hispánico, ilustrado con la edición en apéndice del Encomio sexto al felicísimo Nascimiento de la Virgen, del P. Juan de Cigorondo». Teatro breve virreinal. Miguel Zugasti (coordinador). América sin Nombre, 21 (2016): 21-37, DOI: 10.14198/AMESN.2016.21.01

Link para este artículo: http://dx.doi.org/10.14198/AMESN.2016.21.01

\title{
Teatro breve escolar virreinal hispánico, ilustrado con la edición en apéndice del Encomio sexto al felicísimo Nascimiento de la Virgen, del P. Juan de Cigorondo
}

\author{
Brief Humanistic and School Hispanic Colonial Theater, illustrated in Appendix with \\ the text of the Sixth Encomium to the most happy Birth of the Virgin, by Fr. Juan de \\ Cigorondo
}

\author{
Julio Alonso Asenjo* \\ Universitat de València
}

\section{Resumen}

Presentación de la producción de teatro breve escolar virreinal hispánico, siguiendo sus géneros: diálogo, égloga, loa, encomio, decuria, entremés y, en forma parateatral: mojiganga, danza y baile, juego, vejamen. En apéndice se edita el texto de un encomio de Juan de Cigorondo.

Palabras clave: Teatro breve, escolar, virreinal, hispánico, edición encomio.

\begin{abstract}
Spanish colonial short school drama exposition by its main genres: dialogue, eclogue, loa, encomium, decuria, interlude and theatre related masquerade, dance, game, vexamen. In Appendix, the edition of a Juan de Cigorondo's encomium.
\end{abstract}

Keywords: Short Theatre, School Drama, Spanish Colonial Encomium.

Son relativamente pocas las muestras textuales del teatro virreinal hispánico pertenecientes al ámbito humanístico y escolar. De ofrecer una panorámica de esta modalidad teatral me ocupé hace ańos (Alonso
Asenjo 2008-2009, 2011). En ella quedaron englobadas las escasas muestras de teatro breve o parateatro que conservamos, como era de esperar de unas obras de circunstancias, cuya finalidad se agotaba en

* Julio Alonso Asenjo (1942) es doctor en Filología Hispánica. Tesis: la Comedia de Sepúlveda (Londres, Tamesis Books, 1990). Publicaciones con edición de textos especialmente del antiguo teatro humanístico y escolar hispánico: La tragedia intitulada Oçio de Juan Cigorondo y el teatro de colegio novohispano del siglo XVI, México, 2006; Teatro colegial colonial de jesuitas de México a Chile, Valencia, 2012. Dirigió TeatrEsco. Revista del Antiguo Teatro Escolar Hispánico. Ahora mantiene el Portal TeatrEsco dentro del Proyecto Parnaseo de la Universitat de València. 
el acto de ejecución. El azar quiso que, más allá de las noticias, quedaran, cuando no textos, al menos sí descripciones de tales actuaciones.

Parece oportuno dar razón aquí de ellas con cierto orden, exponiendo brevemente sus características y describiendo su circunstancia. Previamente, sin embargo, habrá que proceder a algunas aclaraciones, pues no siempre es fácil decidir o definir unívocamente la brevedad de tales actos. Mientras en el teatro general el género define la extensión de una obra o duración de su representación y, así, son teatro breve entremeses y sainetes, pero no tragedias, tragicomedias o comedias, no resulta tan fácil catalogar dentro de la brevedad del teatro un diálogo, un coloquio o una égloga, ni aún un intermedio o entremés que, con el nombre de "entretenimiento", puede constar de tres partes y de notable extensión ${ }^{1}$. Como a veces, por lo dicho, el género deja en la indefinición la categoría de una obra, como en el caso de una égloga o de un diálogo que puede tener en el primer caso no menos de 2000 versos y apenas 25 en otros, consideraremos teatro breve desde aquellas obras que tengan una duración de menos de media hora o de unos 500 versos. No se recogen aquí las noticias de representaciones, cualquiera que sea el género, si se trata de autos públicos, caso de los Diálogos del Santísimo Sacramento (F 1154)² y si se desconoce la extensión del texto o duración de la representación.

Comienza la exposición a partir de los actos que impliquen textos de los que al menos tenemos noticia, para, a continuación, ocuparnos de actuaciones de formas parateatrales, teniendo en cuenta las fechas de diálogos y coloquios, de églogas o entremeses, de decurias o encomios, que implican acción con pluralidad de agentes, para pasar después a formas más bien monologales como loas o vejámenes. En último lugar, de modalidades parateatrales como juegos, danzas y bailes, máscaras o mojigangas (y aun procesiones y paseos), especialmente si tienen alguna representación en su decurso.

1. Tal es el caso del «entretenimiento» modernamente titulado Hércules libertador de la Ciencia, intermedio de la Tragedia de San Hermenegildo, que consta de no menos de 1894 versos (Alonso Asenjo, 1995, vol. 2).

2. Para abreviar explicaciones y referencias bibliográficas, se añade $\mathrm{F}$ seguida del número de ficha, a partir del Catálogo del Antiguo Teatro Escolar Hispánico (CATEH), base de datos de TeatrEsco, al cuidado de Julio Alonso Asenjo: <http:// parnaseo4.uv.es/fmi/iwp/cgi?-db=Catalogo-Antiguo-TeatroEscolar_Server\&-loadframes>.

\section{Diálogos}

Parece oportuno iniciar la presentación de estas formas de teatro breve con los diálogos y, dentro de ellos, con los que en México continuaron la Linguae latinae exercitatio que escribió Luis Vives. Otro maestro hispano trasladado a la colonia añadió siete diálogos latinos del mismo estilo «en beneficio de la juventud estudiosa» (Cervantes de Salazar 7). Este autor, Francisco Cervantes de Salazar (Toledo, ca. 1514 - México, 1575), que aprendió latín con Alejo Venegas, estudió Cánones y Teología en Salamanca, aunque ante la Universidad de México, en principio, alegó los títulos de maestro en Artes por Alcalá y doctor en Teología por Sigüenza, había sido catedrático de Retórica en la Universidad de Osuna e, incorporado a la de México, pronunció la oración inaugural de la Universidad y fue profesor de Retórica en ella desde 1553 a 1557. En 1554 publicó con comentario, en México, Ad Ludouici Viuis Valentini exercitationem, aliquot Dialogi / 'Varios diálogos, añadidos a los de Vives' (F 2530). Cuatro de esos diálogos había él compuesto en España sobre juegos contemporáneos: 10: Saltus / Salto; 20: Ludus sphaerae per anulum ferreum / Juego de bola a través de un aro; $3^{\circ}$ : Obeliscorum seu lignearum pyramidularum ludus / Juego de bolos. 4o: Pilae palmariae ludus / Juego de pelota. Otra serie de tres compuso ya en la Ciudad de México, sobre esta capital y alrededores: 5०: Academia Mexicana / La Universidad de México; $6^{\circ}$ Civitas Mexicus interior / México ciudad interior; 7o Mexicus exterior / Alrededores de la ciudad de México. El objetivo era utilizarlos él y sus colegas como base para ejercicios escolares en modalidad muy cercana al teatro, si no teatral en sí misma, como sucedió en alguna universidad española con los Colloquia de Erasmo ${ }^{3}$.

De diálogos o coloquios y oraciones o discursos en colegios conservamos algunas noticias. Algo semejante a representaciones o ejercitaciones escolares se dieron ya en el Colegio de Santa Cruz de Tlatelolco, fundado por el obispo fray Juan de Zumárraga y en funcionamiento desde 1536, donde, por su estudio de la Retórica, varios alumnos eran capaces de hacer discursos en latín (Rubio Mañé 7). Es otra manera de formar a los estudiantes en el conocimiento del latín y de la elocuencia y porte, coincidente con los objetivos de las representaciones teatrales.

3. Así está documentado para la de Valencia, 1537, cuando se representaron unos «Colloquis de Herasme» (F 761). 
También sabemos de breves representaciones en la semana del recibimiento de las reliquias en la Ciudad de México, junto a la gran Tragedia del Triunfo de los Santos (1578), por alumnos de los colegios de la Compañía. En el Diálogo de Amor y Temor, parte en hexámetros latinos y parte en metro castellano, el tercer día de los festejos por la llegada de las reliquias, martes 4 noviembre 1578 , por los estudiantes del Colegio de San Gregorio (F 931), Amor y Temor disputan sobre quién de ellos había prevalecido en los santos. Intervino el coro, siguiendo una «danza graciosa» con que dieron fin a la obra, en la que no faltaron «muy buenas canciones y villanescas, y tres graciosos entremeses a propósito, y en particular uno de pobres (que de diversas partes del mundo se fingían haber venido a esta celebridad) dio mucho contento» (Mariscal Hay 227-229).

Coloquio del martirio y la virginidad en la misma circunstancia, por los estudiantes del Colegio de San Bernardo, miércoles 5 noviembre (F 932). La Fama proclama la buena noticia de las reliquias. Se encuentra con peregrinos de tierras extranjeras, con los que habla en sus lenguas respectivas. Aparece el personaje del Mundo, de malo, con el que luchan una virgen y un mártir. Dos coros expresan alabanzas del martirio y la virginidad (Mariscal Hay 229-230).

Coloquio de ángeles con sarao alegórico, en el quinto día de los festejos, por los estudiantes del Colegio de San Miguel, jueves 6 noviembre 1578. Coros de ángeles se dirigen a adorar las reliquias. Un grupo de niños también proclama que Dios los ha enviado a venerarlas. Al sonido de dos instrumentos, los ángeles, dirigidos por un serafín, comienzan una solemne y graciosa danza. Acabada, se inclinan ante las reliquias y se van. Queda «un simple haciendo un entremés gracioso y a propósito, con que se dio fin al coloquio» (Mariscal Hay 230-232).

Coloquio de México enriquecido por las reliquias (F 934), en el mismo marco, por estudiantes del Colegio Máximo de San Pedro y San Pablo, viernes 7 noviembre 1578, con una segunda representación a solicitud de la Real Audiencia de México. Abre el espectáculo una danza de ocho niños, ricamente vestidos. Entran luego dos estudiantes. El argumento retrata a México, colmado de riquezas pero abrumado por el pecado. Convertido, busca consuelo espiritual solicitando reliquias de santos a Roma. México aparece representado por un joven con un atuendo "mezclado de español y de indio» (Mariscal Hay 232-234). La representación, en que se incluyeron "graciosos entremeses», termina con el coro cantando un motivo apropiado.
Coloquio de Interés y Honor (F 93), séptimo día de los festejos, antes de la distribución de premios del certamen poético en loor de los santos, en presencia del virrey, miembros de la Real Audiencia y de ambos Cabildos. Interés y Honor disputan sobre sus respectivos poderes. Un villancico aclara el significado. Vienen luego Poesía, buscando a Interés, y Oratoria (Retórica), a Honor. Religión se quejará a Justicia de que Poesía y Oratoria no utilizan bien sus talentos en alabanza de Dios y sus santos. Justicia dictamina que ambas deben exaltar a Religión. Tras esta conclusión, un heraldo sube al trono para anunciar a quién se han otorgado los premios de los certámenes. De este modo, con gran acierto espectacular, se unifica en un acto total la representación propiamente dramática y teatral con un acto parateatral como es la ceremonia de la concesión de los premios del certamen poético (Mariscal Hay 234-236).

Destacamos por su originalidad, además, que durante la procesión del primer día de los festejos por las reliquias, ante el cuarto de los arcos de triunfo, los estudiantes del Colegio de San Bernardo miman una acción (F 930):

Detrás de los Sanctos Doctores estaban muchos estudiantes colegiales con sus mantos y becas, puestos de rodillas y los bonetes en las manos, mirando también al sol dicho, como los Doctores, dando a entender que toda la luz e intelligencia que ellos, estudiando, hallaban en los libros de los Sanctos Doctores, procedía de Cristo, sol de justicia (Mariscal Hay 68).

El P. José Acosta había pasado al Perú en 1571, donde permaneció hasta 1586. Entre otras actividades, fue también rector de los colegios de Lima y Arequipa, y Provincial de 1576-1581. Él, que a sus 15 años había compuesto una tragedia de extensión, mantuvo su aprecio del valor educativo del teatro, por lo que en 1589, de paso por Sevilla como Visitador, se le honró con la representación del Diálogo hecho a la llegada del P. Visitador del P. Francisco Ximénez (Alonso Asenjo, 1995, vol. 1). Pero lo que a nosotros interesa, más allá de saber de su admiración por la actuación de estudiantes de la doctrina de Juli, sobre el lago Titicaca, en Perú, pese a no entender el texto, recitado en lenguas indígenas (1578; F 1037), es el hecho de haber compuesto un opúsculo suyo que circuló manuscrito titulado: Orationes y diálogos en latin y romance para que se exercitassen los estudiantes y los representassen al pueblo, como al parecer sucedió (Pascual Barea 591), aunque no nos consta la extensión de estas piezas (F 910). 
Diálogo anónimo de cuatro escolares, A B R C, que llamamos Mutación feliz (F 307), al recibimiento en un colegio del Sr. Arzobispo de México, Pedro de Moya Contreras, en el decimotercero aniversario de su llegada a México: 1584, en 404 versos $^{4}$. Se inicia con lamentos por la disciplina y trabajo de la condición estudiantil que a algunos lleva a pensar en la huida. Pero, alertados en sueños, en la intervención del arzobispo reconocerán cambios decisivos en sus vidas («mutatio felix»), hallando ahora placer en lo que antes encontraban disgusto. Planteamiento original y marcado artificio de la estructura.

Por los mismos años, de idénticas circunstancias de visitas o recibimiento de personalidades, tenemos dos diálogos del P. Bernardino de Llanos de género eclógico. El primero de ellos, también de 1584 [Dialogus] Pro patris Antonii de Mendoza adventu [factus], de 1584 (F 870; 468 versos hexámetros o dísticos). El segundo, del mismo autor, representado en 1589, se titula Dialogus in adventu inquisitorum factus (F 871; 366 versos hexámetros o dísticos), texto traducido y editado modernamente por Quiñones Melgoza (87-95). Por su extensión, 1058 vv., que lo constituyen en obra mayor, no integramos aquí el Colloquio a lo pastoril a la electión del P. Provincial, de Juan de Cigorondo, Ciudad de México, 1598, recientemente estudiado y publicado su texto (Alonso Asenjo, 2012, 21-120).

\section{Églogas}

De los diálogos o coloquios, por su apertura al tratamiento dialogado de cualquier tema, no están lejos, como género, las églogas, como ya se ha visto en los textos recién citados, que bien podrían denominarse también églogas. Incluso en diálogos como la Mutación feliz, la alternativa que los estudiantes ven a su azarosa existencia es la vida al menos en contacto y armonía con la naturaleza. La novedad de la égloga es el uso de lo pastoril como alegoría continuada. Pocas son las piezas breves del género de la égloga conservadas en el ámbito virreinal concreto de la Nueva España, en su inmensa mayoría gracias al Ms. 1631 de la Biblioteca Nacional de México, casi todas con previsible representación o recitación en alguna circunstancia, salvo la Chronidis ecloga, composición no original y más bien elegía. Cuatro églogas, tres custodiadas en el Ms. 1631 y

4. Próxima publicación en Taller de TeatrEsco. una recientemente reconocida en un Cartapacio de la Biblioteca de la Real Academia de la Historia de Madrid, de B. Larios, «ad Concilium Mexicanum» III, que se celebró en 1585 , por su contenido, debieron recitarse por las fiestas del Corpus de ese año ${ }^{5}$. Son églogas breves de 25 o 26 versos, en que se expone la problemática conciliar con alabanza particular del arzobispo convocante y también virrey. Del P. Llanos tenemos la égloga dedicada al P. Azebedo y socios (De felicissimo R. P. Azebedi et sociorum martyrio), martirizados al sur de Canarias, cuando se desplazaban hacia las misiones del Brasil. Luis Peña, de quien poco sabemos, compuso, como poema de recibimiento, la égloga De adventu Proregis Ludovici de Velasco, que se leyó en ese acto (Osorio Romero 1979, 60) y en estos ańos de progreso de los estudios en los colegios de los jesuitas compuso la Protheus ecloga, Vaticinium de progressu in litteris Mexicanae Iuventutis, que debió de leerse en una visita de virrey al Colegio. Durante una celebración del Corpus, hacia fines del siglo xvi, hubo de recitarse alternativamente la Égloga de Amintas (Daminthas en otra copia) y Silvano, vinatero y segador respectivamente, que en sus oficios representan alegóricamente el pan y el vino del Sacramento. Tiene una extensión de 110 versos. Finalmente, hallamos una Égloga de la Vida de San Ignacio, 1627, que pudo tener entidad autónoma con tal contenido hagiográfico y posteriormente se representó como prólogo ante la anónima comedia titulada Vida de San Ignacio (F 2082), por los años de la canonización del fundador de la Compañía de Jesús, en 1622.

\section{Loas}

Las loas eran inicialmente monólogos sobre diferentes temas, liminares de un espectáculo teatral, que evolucionan a piezas dialogadas y amplias y aun independientes o autónomas en el siglo XVII. Así desarrolladas, se cultivaron en los territorios hispánicos de Ultramar especialmente desde fines del siglo XVII (Pasquariello, Irving), aunque posiblemente con menor evolución, ya tenemos varias desde principios de este siglo: Manila, 1601, 1611 y 1676; Quito, 1648.

Su cultivo podría considerarse característica ultramarina, por ser uno de los géneros que está en la raíz

5. Publicadas por Alonso Asenjo como «Las cuatro églogas al Concilio Mexicano III»: Taller de TeatrEsco, 2016. 
o inicio de literaturas nacionales, como la argentina ${ }^{6}$, filipina y hasta la ecuatoriana, por más que no fuera «a suitable literary vehicle for the national spirit which was to develop in the nineteenth century» (Pasquariello 18), ni siquiera en el Río de la Plata.

La loa arraigó particularmente en Filipinas, integrada en el mismo movimiento. En cualquier lengua, en verso, declamada, pero en muchos casos con intercalaciones musicales o completamente musicada, sus textos se publicaban a menudo, pues servían para propósitos específicos de refuerzo de la lealtad política (Retana 37s; Irving). Las loas filipinas "pronto comenzaron a cundir por el país» y duraron hasta el fin de la dominación española. Por todo ello, hubiéramos querido poner las loas entre las características que distinguían a Ultramar de la metrópoli, que habría de haberlas tenido, ya por su carácter circunstancial (se escribían para una ocasión concreta de celebración $)^{7}$, frente a los textos centrales de la representación mayoritariamente venidos de la metrópoli. Parece, por tanto, que podrían normalmente haber reflejado la problemática de los territorios de la colonia. Como es lógico, estas características difícilmente pudieron darse en las loas escolares, muchas de las cuales se ejecutan con ocasión del recibimiento o en honor de personalidades oficiales como obispos (tal sucedió en Quito, 1648, F 2329, y en Potosí en 1716 con dos loas), virreyes (así en México, 1756, F 2220 -ver Luciani 2008-, y en Bogotá en 1773, F. 2541), o para mayor honra de una orden por la celebración propagandística de la santidad de algunos de sus miembros (así en Manila, jesuitas en 1611, F 2211; dominicos en 1676, obra de fray Felipe Pardo, F 1069 y 1070).

Entre las muchas loas producidas en el Ultramar hispánico (sola Sor Juana compone no menos de dieciocho), tenemos datos de quince de ellas con valor dramático pertenecientes al ámbito escolar (las dos primeras en Manila, 1601) y de varias de las cuales conservamos el texto: tres son de Filipinas, dos de Quito $^{8}$, tres de Potosí y una de Bogotá, más tres de

6. La loa supone un hito en la literatura nacional argentina, desde la de Antonio Fuentes del Arco, recogida de una Carta Annua de los jesuitas de Santa Fe, considerada la primera pieza dramática de la literatura producida en Argentina, que ha merecido numerosos estudios.

7. Tal es el rasgo fundamental de la loa, que evolucionará hacia un marco particular en el siglo xviII. Remito a los trabajos de Zugasti $(2002,2006)$ y Farré Vidal (2003, I: 5-7).

8. Una del P. de Antonio Bastidas (F 2329) y otra que se representó en 1743 a la elección del obispo de Quito, D. Juan
Nueva España: dos del P. Cigorondo, de fines del s. XVI o primeros ańos del XVII (Alonso Asenjo, 2002), y la que presenta el Auto del Mártir del Sacramento de Sor Juana Inés de la Cruz (ca. 1685), que muestra un considerable desarrollo (500 vv.), con temática y representación de Seminario Conciliar (disputa teológica sobre la mayor fineza de Cristo), aunque pensada teniendo como primer objetivo un público muy selecto, como la Corte de Madrid. Estas loas novohispanas, como la de Bastidas, revelan varios rasgos de las representaciones escolares y apenas enmascaran el Prólogo y Argumento de representaciones humanísticas, como reconoce el P. Cigorondo en la loa del segundo de los Coloquios al SSmo. Sacramento: «Mas ¿dónde voy, que he trocado / en Prólogo aquesta Loa, / y repito sin provecho / lo que ha de enseñar la historia?» (vv. 33-36, en Alonso Asenjo, 2002). Lo mismo podemos afirmar de la loa de 136 versos del P. Bastidas en Quito (F 2329), que precede a la representación de una comedia (de la que no conocemos el texto), en honor de Nuestra Señora de Guápulo, según leemos en su final: "Reconocidos a aquesta / (no se tenga por lisonja) / una comedia ofrecemos, / corto festejo a tu gloria» (Espinosa Pólit). Y el mismo objetivo tuvo la loa de Peralta Barnuevo (F 2373), que precedió a la representación, en el Seminario de Santo Toribio de Lima, de Lances de amor de Calderón en 1744.

Sin embargo, aunque no se haya conservado el texto, en el Coloquio de la Concepción representado en Santiago de Chile (1732), en la despedida se anuncia la recitación o canto de una loa en vizcaíno ("para alabar a María, aunque con su media lengua», vv. 1974-1975), bien adaptada a las circunstancias de la fiesta (Alonso Asenjo, 2012: 167 y 278)

Pero, pese a las posibilidades de la loa de incidir en la realidad social, solo la de Sor Juana (como otras no escolares suyas) $)^{9}$ toca un tema importante para los territorios ultramarinos ${ }^{10}$, como es el descubrimiento de América, hazaña que, en la perspectiva de

Nieto y Polo (F 2341), cada una de estilo distinto, de acuerdo con la evolución cronológica del género.

9. En el marco de una típica disputa escolástica, con recurso a autoridades y silogismos, entre estudiantes, que en alguna representación pudieron ser al mismo tiempo personajes y actores.

10. No lo era menos para la metrópoli y sus cortesanos, cuyo poder sostenían las Indias. De ahí las «iAlbricias, Europa, albricias! / Más mundos hay, más imperios, / que tus armas avasallen / y sujeten tus alientos» (loa para El mártir del Sacramento, vv. 254-257). 
la autora, corrige la hercúlea del Non plus ultra ${ }^{11}$. Sin embargo, en lo demás no se aprecia en las loas escolares de Ultramar diferencia con las metropolitanas, ni en cuanto a la frecuencia de representación, ni por el tipo de las piezas escolares de Órdenes que desarrollaron con plenitud su actividad en la Península especialmente en el siglo XVIII, como son los escolapios. Por tanto, el cultivo de la loa autónoma o en un marco festivo general parece ser producto de la evolución cronológica y en el ámbito escolar la tenemos mejor certificada para unos territorios que para otros.

\section{Encomios}

El encomio, aquí, es una composición dramática laudatoria. Puede relacionarse con la loa, que fue adquiriendo también factura dialógica. En nuestro campo, el encomio es una sencilla representación escolar de encarecimiento de personas, valores y virtudes. Del teatro escolar virreinal solo conocemos los ocho Encomios al felicissimo Nasçimiento de la Virgen en la colocaçión de l[a] ymagen, que custodia el Cartapacio curioso de algunas comedias del P. Juan de Cigorondo (BNE, Ms. 17286, fol. 124v-168r) ${ }^{12}$, cuadros escénicos que suman en conjunto unos 1800 versos (F 858).

Maldonado Macías data la representación en 1595, cuando Cigorondo se traslada a Guadalajara, promovido a Rector del Colegio de Santo Tomás. Será «su primera estancia de dos o tres años» allí (Maldonado Macías 1990, 181). Pero hay que pensar más bien en 1596, cuando ya era profesor de Retórica en ese mismo colegio, curso 1596-1597 (Osorio Romero 1979, 287), en la octava de celebración del nacimiento de María, desde el 8 de setiembre. Así consta en la Annua de 1596 del Colegio de Guadalajara, enviada desde México el 1 de marzo de 1597 (Monumenta Mexicana, VI, 57, n. 106, p. 214).

Más detalles sobre la representación de estos encomios, en la edición del Encomio sexto que va en Apéndice de este mismo estudio.

11. Colón con soldados y Hércules aparecen como personajes de la loa, junto a los estudiantes (3) y los coros. Sobre esta obra de Sor Juana Inés, ver F 2312.

12. Maldonado Macías (1990) ha editado el Encomio quinto, que ocupa los fol. 145r-152r. Ver también Maldonado Macías, 1995.

\section{Decurias}

Las decurias, en su origen, eran diálogos a modo de preguntas y respuestas del catecismo, por el estilo de los diálogos de los humanistas, para ejercitación de los estudiantes, organizados en grupos de diez, como práctica para la retórica, declamación y el aprendizaje en la misma clase. Derivaron en piezas teatrales breves y de pocos personajes, para ejercitar la declamación, reforzar la formación y excitar la devoción propia y de la audiencia, que podía ser externa. De 14 de ellas, de entre 1700 y 1740, en el Perú, conservamos el texto, obra de los Padres Buendía, Palomino, Prieto, Vega, jesuitas, y otras anónimas. Mediante estos diálogos se instruía a los niños con preguntas, respuestas, relatos u otras formas, para inculcar de un modo activo, por participativo, en la exposición de conceptos y elementos doctrinales o morales del catolicismo (Vargas Ugarte) ${ }^{13}$.

\section{Entremeses}

Según su significado más común, entremés es una pieza teatral breve de carácter cómico, que se representaba en el entreacto o los entreactos de una comedia. Y en términos generales así sucede en la época y campo del teatro escolar que nos interesan. Es frecuente que al hablar de comedias (en nuestro caso también de tragicomedias, diálogos o coloquios) no se mencionen los entremeses que las acompañaban, que en el teatro de los jesuitas se llamaban hasta tiempos más recientes "actiones intercalares» $\mathrm{O}$ "actiones ioculares» y también "entreactos» o «entretenimientos». A veces estas acciones intercalares o de diversión, que son auténticos entremeses, aparecen literalmente intercaladas entre las escenas ordinarias; otras veces ocupan el último lugar de las de un acto. Ambas situaciones se dan en la Tragedia intitulada Oçio de Cigorondo ${ }^{14}$.

Estas escenas o piezas breves a menudo no se copiaban para su conservación o, si acaso, se ponían al final del texto. De ahí que tantos se hayan perdido y solo recientemente se vayan publicando conjuntamente varios de los colegios de jesuitas de la

13. En el CATEH se aconseja buscar por «decuria» en sección "Título», o en las fichas 921, 959, 960, 2076, 2078, 2350, 2362-2365, 2566, 2568, 2569.

14. Ver Alonso Asenjo, 2006: XC-XCII, con intercalación en forma de coro en III, 2, vv. 2278-2349 (pp. 132-134) y al fin de II, 3, vv. 1768-1940 (pp. 92-99). 
Península Ibérica (Menéndez Peláez). Es mejor definirlos como piezas jocosas breves sin atribuirles un solo acto, porque a veces pueden tener incluso tres, aunque se llamen «partes». Como la loa, el entremés fue ganando autonomía y recibiendo otras denominaciones como sainete o farsa, que se representaban sin dependencia de piezas más extensas, o formando parte de un conjunto de actos festivos como danzas, sarao, pasos escénicos, mojigangas... Como unas loas, según una relación, se representó en el marco festivo de 1676 en Manila el Entremés del envidioso de fray Felipe Pardo en Manila (F 1068) y con pasos escénicos representaron entremeses escritos por la madre Juana de Herrera y Mendoza (ca. 1690-1705, F 954), autora también de endechas religiosas y de loas, para diversión de novicias de las clarisas de Lima (Forgues 96).

Si consideramos estos hechos y que son pocas las piezas extensas de teatro escolar virreinal que conservamos, ya podemos suponer que no son muchos los entremeses conocidos. Dos más, en fin de un Coloquio de los colegios menores que celebraron la llegada de las reliquias a Nueva España de las que nos da razón el P. Morales en su Carta de descripción de esta semana de festejos (F 923 y 934). Uno (Entremés del examen de candidatos a órdenes) se menciona en el Coloquio del Santísimo Sacramento del P. Cigorondo (F 862; Alonso Asenjo, 2002), otro en la Comedia de San Ignacio de Loyola del P. Bocanegra (F 874), y uno más en la visita del virrey al Convento de San Jerónimo de la Ciudad de México (F 2220), junto a otros entretenimientos, como ocurre igualmente en 1611 en Tinagob, hoy Cebú, en Filipinas (F 1054), y «danzas por entremeses» se nos dice que bailaron los niños de la parroquia de San Miguel, junto a Manila (F 1047), durante la representación de un coloquio. Un entremés representado por «indios», con bastante indecencia (añade la fuente), que a duras penas cabe en ámbito de lo escolar, si no es porque se representó en el Colegio de los jesuitas de Asunción, 1637 (F. 2145); y conocemos uno llamado Farsa del pastelero, que se representó en Puebla (F 2400) en 1650, y de Santiago de Chile representaciones de «entremeses y sainetes» en 1693 (F 2491).

Probablemente lo más cercano a la práctica antigua del entremés que tenemos en el teatro escolar es el Entremés (sin título), representado en Santo Domingo en 1588, que lo fue en la fiesta del Corpus (F 2225), como entreacto en los festejos ciudadanos, por estudiantes del Colegio Gorjón, del cual era profesor el autor, Cristóbal de Llerena. El texto se ha conservado debido a la denuncia y proceso penal incoado al autor, en el que se adujo como prueba de las intolerables críticas de la vida pública de la colonia puestas en boca de un monstruo de resonancias clásicas $^{15}$.

A este podemos añadir otros dos de los que conservamos el texto. El primero titulado El galán liberal, que también debemos a la denuncia que sufrió. Lo representaron, con el auto o comedia Narciso sacramentado, los estudiantes del colegio de San José de los jesuitas de Manila en 1754 (F 2399); es de considerable extensión, en dos partes y con 1228 versos.

Otro es el entremés satírico titulado Láurea crítica, de Fernando Fernández de Valenzuela, estudiante del colegio de los jesuitas, de trece ańos, compuesto en Bogotá, 1629, ejercicio literario quizá sin ilusiones de verlo representado. Se trata de un texto que funciona estructuralmente como una visita de locos, entremés satírico de varios tipos en caricatura, con la teatralización de su examen y especialmente de un ceremonial de una graduación de doctor, vejamen e investidura incluidos. Es una breve pieza que imita entre burlas el estilo gongorino, emulando entremeses de autores satíricos de última hora en la corte, que estructuran la secuencia del examen y vejamen para concesión del grado de crítico al caballero don Velialís o Belianís de Lúbricis, cuyo solo nombre evoca escenas típicas de investidura de libros de caballerías adoptadas en el mismo otorgamiento del grado de doctor; al mismo tiempo sigue de cerca la Fábula de Polifemo y Galatea del vate cordobés y juegos verbales del Vejamen del mismo Góngora ${ }^{16}$.

15. Sobre las circunstancias de su representación, proceso judicial consiguiente, descubrimiento, ediciones y estudios, puede verse CATEH, F 2225. Debemos el conocimiento del texto a su hallazgo en el Archivo de Indias por Francisco A. Icaza, 1921. Llerena construye su entremés sobre aportaciones de clásicos grecolatinos, como la referencia a un pasaje del Arte poética o Ad Pisones de Horacio, con cuyos elementos teje el Monstruo y las figuras de Proteo, Edipo, Calcas y Delio, para criticar las torpezas de las autoridades de la colonia en la conducción de los asuntos económicos y sociales. Madrigal destaca en la pieza el «lenguaje del teatro de colegio» (325).

16. Aquí está un «Polifemo» y también "Tenemos un doctorando», «En este de las sciencias fiel protótipo» (v. 383 ss). Y a su vez: «una ves oí, por no ser sordo, / que doctor, convertido breve, es sordo» (v. 395). Al mismo vejamen, dado en Granada, remite en especial la insistencia en la primera sección sobre el Orate, fratres (vv. 290-317). 


\section{Parateatro}

Se incluyen en esta sección mojigangas parateatrales, danzas y bailes ${ }^{17}$. Mojigangas parateatrales, también denominadas no dramáticas o callejeras, y máscaras o mascaradas, paseos o desfiles, triunfos y aun procesiones, que "son la suma de una serie de módulos generalmente duales, en los que solo existe el disfraz y lenguaje escrito en el mote» (Lobato 575). Se distinguen de las teatrales o dramáticas por no representar acciones conjuntas o dialogadas. Los triunfos, además de la monumentalidad de los carros o carrozas, suelen implicar personajes alegóricos y presencia de emblemas y a menudo representaciones teatrales breves o declamaciones sobre ellos o con descenso de los mismos a escenarios efímeros; las procesiones, que no incluyen los tipos de la mojiganga parateatral, remiten a una manifestación religiosa más que figurativa. A esta recurren habitualmente instituciones como ciudades o ayuntamientos, gremios ciudadanos, parroquias, congregaciones e instituciones religiosas, universidades y colegios ${ }^{18}$.

Con arranque en la participación de los muchachos en actos públicos multitudinarios y procesiones sobre todo del Corpus ${ }^{19}$, los escolares y estudiantes tenían presencia destacada en manifestaciones con ocasión de la llegada de reliquias, mercedes romanas para el culto mariano (concepcionista especialmente en el siglo XVII), festividades del Corpus, recibimientos de obispos y sobre todo de virreyes (México, 1650, F 2507), coronación o casamiento del rey (México, 1724, F 2370 y 2401), toma de posesión de una cátedra (México, 1721, F 2407), etc. Participaban en ellas centenares de estudiantes, luciendo indumentarias o disfraces, a caballo, a pie y en carros triunfales, en lo que compiten ciudades, órdenes religiosas y colegios en suntuoso derroche y fausto espectacular.

En México fueron grandiosos los triunfos organizados por la Universidad para honrar la Concepción desde 1619 (F 2361) y, entre tantas ciudades, destacaron México en 1622 (F 938, 2153) y Puebla en

17. Para las obras de los géneros musicales como zarzuelas u oratorios del territorio virreinal, se remite a Alonso Asenjo, 2014.

18. Hay breve referencia a ellas en Alonso Asenjo (2008-2009). Las relaciones de actos de este tipo para el ámbito general hispánico son muy numerosas.

19. Aunque especialmente dedicado a grupos específicos de muchachos, es interesante en este contexto el artículo de García Reidy (2008-2009).
1623 (F 1031, 1075), porque "no se podía haser más» (dice una Relación), cuando se celebró la canonización de Ignacio y Francisco Javier (Alonso Asenjo 2007). Dos máscaras se hicieron en México por la canonización de Francisco de Borja, según fuentes, en 1671 (F 2079), y según otras, otras dos máscaras en 1672, también grave y faceta (F 1024), ejecutadas por los estudiantes, que «salieron más de cuatrocientos enmascarados y muy lucidos carros» (Robles, vol. I, 113) ${ }^{20}$. Una máscara reivindicativa a lo faceto organizaron los estudiantes en Puebla en 1650 (F 2507) y no debemos olvidar un vítor y paseo de campanillas para celebrar la toma de posesión de un catedrático de la Orden de la Merced en 1721 (F 2407). En el año 1611 en Bogotá (F 2326) se recibieron reliquias de San Victorino con saraos y una máscara en el marco de los festejos habituales, "con el aparato que se le pudo dar en la tierra" (Mercado, vol. I, 70). En Manila, celebrando la fiesta de la Concepción en 1620 (F 2321), se organiza una procesión, «que hubiera llamado la atención en la misma corte» (Summers 665 ${ }^{21}$ ).

\section{Danzas y bailes}

La primacía de la palabra en el teatro moderno para los muchachos no implica exclusividad. Bailes o danzas, como herencia del teatro medieval y, sobre todo, como elemento indispensable en la formación del cortesano y hombre moderno, se desarrollan en los colegios y universidades al compás de las piezas teatrales o como pieza de festejos. Gran atracción de las representaciones y espectáculos era la maravilla de niños danzantes, que tanto suelen destacar las Relaciones de celebraciones. Danza de lanzas y adargas bailaron escolares en México en 1578 por la llegada de las reliquias (F 929); y también las hubo en Puebla en 1600 al descubrimiento de una imagen mariana (F 1008) y en 1622, en México, entre tanto festejo por la doble canonización de fundador y misionero en la iglesia de la Casa Profesa de la Compañía, tratárase de danza y baile (F 2153), de una danza morisca (F 2216) o de una danza de

20. A pesar de la propuesta de las fuentes, uno duda de que en tan corto espacio de tiempo y por el mismo motivo se montaran dos festejos tan grandiosos.

21. Mi traducción; la fuente escribe: «remarkable enough to have appeared in Madrid» (Summers 665). 
espadas por niños de corta edad «a modo de batallón» (F 2217). Valgan estas como muestra.

También se promueve el canto, si lo abona el medio cultural en que se imparte la doctrina o enseñanza, como por Garcilaso de la Vega el Inca nos consta de los colegios de los jesuitas de Potosí, Cuzco y Lima, que, aprovechando la facilidad de los indígenas para el canto, montaban dramas musicales que "con tanta suavidad» cantaban los indios (Furlong, 146-147); además, F 2088 sobre la celebración del Centenario de la Compañía de Jesús en una reducción del Paraguay; y también en celebraciones como la fiesta del Corpus (F 2316). Y en la Comedia de san Francisco de Borja del P. Bocanegra en México, 1640 , en la visita del virrey y las restantes autoridades al Colegio (F 874), con el «entremés negro» (en lengua de preto o negro, se entiende); diez niños nobles ejecutan dos danzas y por remate de toda la fiesta se bailó «un mitote o tocotín, danza majestuosa y grave hecha a la usanza de los indios, entre dieciséis agraciados nińos, tan vistosamente adornados» (Frost 78).

«Mitote o tocotín» leemos (también «tocontín»), que se nos dan como sinónimos, aunque al parecer no lo eran tanto ${ }^{22}$. El mitote era, como su nombre indica, una danza indígena tradicional: «Especie de danza que usaban los indios en la que entraba gran número de ellos, ataviados vistosamente» (Diccionario de aztequismos), sentida como condensación de la identidad: «proper identitary artifact to cart the collective memory... it is a form of resistance performed in the continuous state of a silent nonverbal derivate act, essential for the individual and social behavior» (Serna González 22). Aparte de la mención de mitote como sinónimo de tocotín en la Comedia de San Francisco de Borja, se ejecutan mitotes en el teatro escolar virreinal en Puebla, 1623 (F 1031, 1088 y 1089), sin especificar, durante la octava de festejos por la canonización de San Ignacio y San Francisco Javier.

El tocontin era también una danza festiva; mejor, una pieza de canto y danza, pues el mensaje cantado revestía especial trascendencia. Dentro del teatro escolar, encontramos un tocontín al final de la

22. Sobre mitote y tocotín nos brindan documentación antigua los Padres José Acosta (Historia Natural y Moral de las Indias. Barcelona 1591, lib. VI, c. 28) y Francisco Xavier Clavijero (Historia Antigua de Méjico. Londres, 1826, vol I: 361). Estudios modernos son los de Pérez de Ribas, Osorio Romero (1975), Partida Tayzan, Padilla Zimbrón y Sainz Bariáin.
Comedia Primera de la Vida de San Ignacio, compuesta en 1627, que no sabemos si se representó ( $F$ 2301 y 950). Las cuartetas hexasílabas se inician con «Tocontín, caciques». Lo estudia con detalle Padilla Zimbrón. También en la ya citada Comedia de San Francisco de Borja (F 874), cuyas coplas, encabezadas por «Salí, mexicanos», edita Frost al final del estudio y edición de esa comedia (78-79). Y curiosamente un tocotín se ejecutó también en 1677 , en la fiesta del Corpus, cuando en un coloquio 11 niños danzaron "pavanas, canarios y tocotines», es decir, danzas de lo más variado, en el colegio de los jesuitas de Agaña, en la isla de Guaján o Guam, en las Marianas (F 2533).

\section{Juegos}

De los juegos de niños se había ocupado Cervantes de Salazar en sus Dialogos latinos añadidos a los de Luis Vives, y más tarde y con mayor empeño lo hará Rodrigo Caro en sus Días geniales y lúdricos. Son herederos de humanistas como Vittorino da Feltre que, fundador de la "Casa Giocosa» ('casa alegre o casa del juego'), había reivindicado la actividad física y juegos como parte de la educación, de modo que desaparezca o se disimule el sufrimiento y esfuerzo y el alumno se imagine que todo se hace por juego. Por otra parte, en el juego se fomenta la camaradería, la emulación y se desarrollan ingenio y traza. Por ello, junto a la actividad teatral y en ella, aparecen juegos.

Juego de cañas y danza de lanzas y adargas hubo durante la procesión del primer día de los festejos por la llegada de las reliquias, ante el tercero de los arcos de triunfo, frente al Seminario de San Pedro y San Pablo. Se volvió a representar el último día de la octava (19 de noviembre de 1578, F 929). Conservamos una descripción detallada de este juego que tuvo lugar después de varias recitaciones y grandes espectáculos (Mariscal Hay 66).

En las obras dramáticas de Cigorondo es frecuente encontrar juegos de muchachos o muchachos jugando. Más de una lleva este término y tema en el título mismo, como el Juego entre quatro niños (F 868) con pares y nones ("yo mis nuesecicas tengo", fol. 61v), alfileres y arquilla (fol. 62r), de los oficios (fol. 67v). Ahí está también la Egloga seu pastorum lusus (F 864), $1^{\mathrm{a}}$ parte, fol. 1v, en la que, con «do prueben lo que pueden / a una sortija buena» (vv. 150-151), se habla de correr una sortija, lo que se lleva a cabo en la $2^{\text {a }}$ parte, fol. 9r, "como hacerse en corte vemos» (v. 1374). En las Églogas del Engaño, 
el juego de las cañas (fol. 262r ss) y también el trompo (fol. 263v-264r) y el toro de las coces (fol. 264r-266v); el del soplillo en el Encomio V publicado por Maldonado Macías; y el torneo también en Comedia de la Magdalena, III, Elogio 3․ Además, en la Égloga pastoril al Nacimiento del Niño Jesús, los pastores juegan a "fil derecho, / que es juego regoçijado» (fol. 30r), a la braza, etc. La derrota de Amor Profano o Cupido y el hecho de amarrarlo a un poste del tablado (Comedia Magdalena, Elogio $3^{\circ}$, fol. 83v., fol. 86r-87r) evocan el apresamiento y las "prisiones» de Ocio en su Tragedia. Y en verdad que, con su movimiento, colorido y gracia, estas secciones constituyen auténticas joyas de la burla dramática.

«Juegos de manos» se nombran junto a la representación de comedias, máscaras y fiestas literarias para 1630 en Manila (F 1057), y falta tiempo para espigar las numerosas veces que se trata del juego o se practica en el teatro escolar virreinal.

\section{Vejámenes}

En nuestro marco escolar, el vejamen es una reprimenda o reprensión satírica y festiva en la que se dan a conocer y se ponderan los defectos, tanto físicos como morales, de quien va abtener un grado universitario (Madroñal 31-46). Se le buscó el origen en la imitación de una situación gloriosa, la de un general romano en la celebración de su victoria, a quien, para que no se ensoberbeciese, se le recordaba que era un hombre mortal y no un dios. Se trata de una costumbre antiquísima que fue adquiriendo aceptación literaria desde fines del siglo XvI, pero su pleno desarrollo y vigencia se da conforme avanza el siglo XVII (Carrasco Urgoiti).

Vejámenes se dieron en todas las universidades y centros con facultad de conceder grados, especialmente el de doctor, por lo que su número en territorios virreinales es incontable desde sus comienzos en las universidades de México y de Lima. En la de México, que se inició el 3 de junio de 1553, ya el 31 de agosto de ese año determinó el claustro que Cervantes de Salazar hiciese vejamen al Dr. Pero López ${ }^{23}$. De los muchos que de Nueva Espańa conocemos, son 12 los publicados (no el de Cervantes de Salazar), todos del siglo Xviır: 7 de la Universidad de

23. Así consta en el Libro de claustros, fol. 87v (Carreño I, 17).
México, 3 del Seminario de San Luis de Zacatecas y tres en el Colegio Máximo de San Pedro y San Pablo y San Ildefonso de la Compañía de Jesús (CATEH, F 1114, 1115 y 1120). Del Perú están publicados diez: seis son de la Universidad de San Marcos de Lima (CATEH, F 815-817, 1102, 1104, 2306) y uno en la de Cuzco (F 2307).

Confirma que los vejámenes eran práctica generalizada el vejamen «a lo divino» del Coloquio del Santísimo Sacramento en metáfora de doctor de Cigorondo, producido quizá ya a caballo de los siglos XVI y XVII (Alonso Asenjo 2002; Madroñal 492497). Hacia unos mismos usos en las universidades señala la ya considerada Láurea crítica de Fernández de Valenzuela, 1629 (F 2313), compuesta en Bogotá (Rivas Sacconi 66 y ss.; Arrom y Rivas Sacconi), cuya segunda y principal parte sigue el esquema de la ceremonia de graduación de doctor, que consistía en preguntas (por réplicas a la lección del candidato) y aprobación; seguía el ósculo de paz, la entrega de insignias (anillo, libro, borla) y, si no era clérigo, se le ceñía una espada y calzaba espuelas de oro (Jiménez Rueda 15), como en la investidura de los caballeros ${ }^{24}$. Un ritual cuya raíz medieval se había robustecido, tanto para Lima como para México, en la universidad salmantina.

Llaman la atención por su originalidad y frescura los dos vejámenes de P. J. Sánchez de Meza, en Zacatecas, 1788, Teatro de los dioses (F 2531, con edición de Omacini, 1983); República de las aves, 1791 (F 2537) y un tercero de la alegoría de una Huerta frutal, 1797 (F 2538) del bachiller Jacinto Martínez (publicado también por Omacini, 1980). $Y$ conocemos varios geográficamente dispersos. Uno en la Universidad de Córdoba, ca. 1722 (F 819); otro de la Universidad de La Habana, de mediados del siglo XVIII (F 1122; Madroñal 105 y 109 s), y otro en la catedral de Caracas, en Venezuela, 1801, según costumbre antigua, examinado y publicado por Madroñal (499. 502-505).

Una forma de vejamen es el "capelo» (por capirote o birrete de doctor), que indica un repaso o regańina en broma y en son de burla con toques de irrisión e irreverencia que se da al Nińo Jesús. Es una obrita de 196 versos en cuartetas asonantadas. La compuso el P. Juan de Cigorondo (F 2583), y nos

24. A veces el festejo consiguiente, de «vítor» devenía paseo burlesco o grotesco, como el de los bachilleres del Colegio Mayor de Santa María de Todos los Santos, en la Ciudad de México, 1754 (CATEH, F 2323; Carrancá, 25). 
lo han legado el Cartapacio curioso, fol. 356r-361r, y el vol. de la RAH 9-2573, fol. 5r-9r, el cual está publicado modernamente tras el primero de los dos Coloquios sacramentales (Alonso Asenjo 2002; Madroñal 32-34).
Y así queda este repaso del teatro breve escolar virreinal hispánico, aunque con el pesar de no haber podido explicitar más sus piezas para el general disfrute del atento lector. Algo así se intenta en el siguiente Apéndice.

\title{
APÉNDICE
}

\author{
Juan de Cigorondo \\ Encomio sexto al Nacimiento de la Virgen
}

(Guadalajara, México, 1596)

\section{Preludio}

Ya sabemos que la carta annua de 1596 del Colegio de la Compañía de Jesús de Guadalajara dio noticia de la celebración de ocho Encomios al felicísimo nacimiento de la Virgen en la colocación de la imagen, durante la octava de la festividad. Lo hizo con estas palabras:

Tienen especial devoción con la imagen de nuestra Señora del Pópulo que se colocó este año, en nuestra iglesia, el día de la Natividad, con la mayor fiesta que se pudo. Halláronse presentes los seńores de la audiencia, presidente y oidores, todas las religiones y entrambos cabildos eclesiástico y seglar, con todo el pueblo. Recitaron nuestros estudiantes algunas cosas a propósito de la fiesta, la cual duró por toda la octava (Monumenta Mexicana, VI, 57, n. 106, p. 214).

Los estudiantes "recitaron», es decir, representaron, con otros siete, el breve Encomio sexto, compuesto por 150 versos de arte menor. Por extensión, queda cercano al octavo o "último», de solo 120 , pero muy alejado de otros mucho más extensos (el $5^{\circ}$, con 280 vv.; el $7^{\circ}$, con no menos de 404). Está articulado netamente en dos partes: diálogo (vv. 1-114) y coro (vv. 115-150): el primero, en redondillas hexasílabas, que aporta festividad al panegírico; el coro, en cuartetas octosílabas asonantadas. Los personajes son los mismos, dos "serranas / costureras hacendosas", llamadas Flor de Edad y Sencillez, que en la primera parte hablan y en el coro son actrices de la historia contada y cantada.
Las costureras, vienen, por la tarde (vv. 1-10), a asistir al parto con la "cestilla» (vv. 11. 65), que en otras partes llamamos "canastilla»: 'ropa que se previene para el niño que ha de nacer' (DRAE): "pañales», "fajuela», "mantilluela», sobre ellas un corderillo repujado y dijes de azabache para alejar los males, pues presto tendrán «de bien los extremos / en la hija de Ana» (vv. 51-52). En la cesta, materia suavísima, del color del arrebol en el ocaso, cuando revolotean las aves y recrean el aire, invitando a una vida sencilla, que no en vano hablan Flor de Edad y Sencillez. Toda la naturaleza (prado, rosas, azucenas) está "in expectatione partus», esperando a una niña cuyos ojuelos serán esmeraldas bellas; su boca, un rubí. E imaginan el regocijo al verla, fajarla y besarla, mecerla y cantarla con una nana (v. 97 s): sublime sencillez la de la hija de Ana, que alińará la «suerte» de la Humanidad, personificada en unos «chicos» o «sobrinicos (v. 112-113).

Interviene el coro, en la noche entrada en horas, con la luna, plata desgranada en aljófar o perlas (vv. 115-122); las costureras, "aguardando el nacimiento / de una chica y gran señora» (v. 128), hilan y deshilan y guarnecen con joyas, mientras a Ana cuentan las horas y dulces historias que abarcan el sentido del destino de la niña («niña para grandes cosas», v. 130), que será virgen, será desposada y, «sin proveerle padre», le dan un hijo y la coronan: así reciben a la niña y la envuelven y la arrollan. Aplaude el cielo y derrama toda su dulzura (v. 150). 


\title{
Encomio sexto al felicísimo Nascimiento de la Virgen
}

\author{
Flor de EdAd Sencillez
}

FLOR DE EDAD

Amiga, la tarde

[fol. 152v]

nos acorta el día;

ven, que no querría

que amor nos aguarde.

Sencillez

Anda, que no tarda

lo que llega a tiempo,

ni va en vano el tiempo,

FLOR DE EDAD

que Ana nos aguarda.

Sencillez, el fresco

desta tardecilla

a esa tu cestilla

de oro lo agradesco,

que el aire, de vella, muere por tocalla

y se ablanda y calla

Sencillez

para no ofendella.

Flor de Edad, sus faldas

pinta el occidente

de invidia impaciente

desas tus guirnaldas;

diera él de sus perlas

las más y mejores, con que esas tus flores pudiera él tenerlas.

FLOR DE EDAD

Aun las simples aves que revolotean

y el aire recrean con picos suaves sobre la ramilla, al irse a sus nidos mueven los sentidos a vida sencilla.

Sencillez

Amiga, este prado, que así se colora, muestra la mejora que el cielo te ha dado, y la más garrida flor, cuando despunta, los bienes barrunta de la edad florida. 
FLOR DE EDAD

Sencillez

FLOR DE EDAD

SENCILleZ

FLOR DE EDAD

SENCILleZ
Amiga, la rosa

[fol. 153r]

del más rico haber

sin tu rosicler

fuera pobre cosa.

Pues de edad la flor

sin la sencillez

no es más que una tez

que finge el color.

Anda, dulce hermana,

que presto tendremos

50

de bien los estremos

en la hija de Ana,

do, como en vergel,

tendrá, tras tus rosas

y olas olorosas,

azucenas dél.

Esta diferente

guirnalda tejida

la llevo ofrecida

a su limpia frente,

pues la gravedad

de sus dos mejillas

darán florecillas

que adornen mi edad.

Mi cestilla rica

va del ajuar

que hice labrar

para la mi chica.

Con recamo de oro

labré la fajuela

y la mantilluela

me cuesta un tesoro.

Esmeraldas bellas

serán sus ojuelos,

que, a estar en los cielos,

75

sirvieran de estrellas.

Su boca, un rubí

o guinda temprana,

páguelos, oh hermana,

si no fuere así.

60

65

70

Llévole mantillas

de telas delgadas,

unas deshiladas

y otras labradillas,

pañales repuja

de mi rueca y huso

con lo más que puso

mi dedal y aguja.

v. 85 repuja ] cepuja en el Ms., por confusión de r y c. 
FLOR DE EDAD

Qué hartazga he de darme, si llego a fajarla,

de verla y besarla,

para mejorarme;

y aun le cantaré,

si vengo a mecerla

para adormecerla,

un cantar que sé.

A ro, niña, y duérmete,

venga el ángel y guárdete.

Sencillez

Traigo un corderillo

lindo para el pecho,

todo de ámbar hecho

y oro al martillo;

dijes de azabache,

que, puestos al cuello,

puedan defendello

de quien me le tache.

FLOR DE EDAD

Donde así florece

sencillez y edad,

su simplicidad

esto y más merece.

Pues así se aliña, vuestra suerte, chicos, vamos, sobrinicos, veréis a la niña.

SENCILLEZ

\section{vereis a la nina.}

v. 97 A ro, niña] Ms: Arroniña: a ro, o a ro ro, o a la rorro, niño, y aquí niña, son expresiones de uso común aún hoy en día en villancicos de Navidad y en canciones de cuna. Seguramente estos dos versos formaban parte de una contemporánea.

v. 102 oro al martillo: bruñido. Remito al muy conocido soneto de Góngora, de 1582: "Mientras por competir con tu cabello, / oro bruñido al sol [el sol] relumbra en vano" (Sonetos completos, p. 230).

v. 106 le tache: 'le haga daño'. Siguen en el texto dos estrofas más, que copio aquí: "PERICO.- tías de mi vida / mas que nos lleváis, / desa que alabáis / auerla parida. LOR.- Sí mis tías vamos. / JU.- Vamos tías mías. AN.- No nos dexéis tías / y si no lloramos”. Perico, Lor[encico] Ju[anico] y An[tonico] se pusieron aquí sin duda por error desde una copia del texto del Encomio quinto, del que son personajes. Pero este fragmento no aparece en la edición de ese Encomio por Maldonado Macías.

v. 114 Sigue aquí una estrofa asignada a Lor. (por Lorencico), personaje del Encomio quinto. Reza así: LOR.- O coraçoncillo / quando tal pensauas / que esté bien ganaros / jugando al soplillo". Este último verso confirma que esta estrofa pertenecía al Encomio quinto, pues en él se menciona este juego del soplillo en los versos 188 y 261, juego muy antiguo, que describe el Diccionario de Autoridades. 
CHORUS

Levantando pardas nubes, que poco antes eran rojas, ligera tiende las alas la noche ya entrada en horas, escarchando sobre pardo la luna blanca y redonda la plata que desgranada suele volver en aljófar, cuando a cumplir sus tareas se *hallaron a sus solas juntas no sé qué serranas costureras hacendosas, aguardando el nacimiento de una chica y gran señora, dulcísima hija de Ana, niña para grandes cosas; unas deshilan la holanda, otras hilan y otras bordan y entre el hilado y costura le cuentan a Ana las horas. Amor demarca los puntos y el temor se los acorta, y entre si pare o no pare, le cuentan dulces historias. Unas en varias apuestas atraviesan ricas joyas, sobre si naciendo ríe la niña o, en naciendo, llora; unas la consagran virgen, otras virgen la desposan; otras, sin proveerle padre, le dan hijo y la coronan.

Así reciben la niña y la envuelven y la arrollan, y aplaude el cielo y derrama sobre la cuna el ambrosia. [fol. 154r]

115

[fol. 154v]

Chorus: con la eliminación de la estrofa que precedía, perteneciente al Encomio quinto, podría asaltar la duda de que este Coro sea del Encomio sexto. Pero despeja esa duda el reclamo "En", de "Encomio", que sigue al último verso. Además, en la misma línea aparece "Jus", aunque tachado, que remite al personaje de Justicia, que figura el primero tras el título Encomio séptimo en fol. 155r. v. 150 ambrosia: cultismo o licencia del poeta: por 'ambrosía': alimento de dioses. 


\section{Bibliografía}

Alonso Asenjo, Julio. Catálogo del Antiguo Teatro Escolar Hispánico (CATEH). <http://parnaseo.uv.es/Ars/teatresco/BaseDatos/Bases_teatro_Escolar.htm $>$.

Alonso Asenjo, Julio. La "Tragedia de San Hermenegildo" y otras obras del teatro español de colegio. 2 vols. Valencia: Universidad de Valencia-UNED-Universidad de Sevilla, 1995.

Alonso Asenjo, Julio. «Dos coloquios sacramentales barrocos y un vejamen del Cartapacio curioso del $P$. Juan de Cigorondo. Estudio y edición». TeatrEsco, 0 (2002). [Revista electrónica: http://parnaseo.uv.es/ Ars/TEATRESCO/textos/2ColSSmo.htm].

Alonso Asenjo, Julio. "Tragedia intitulada Oçio» de Juan Cigorondo y Teatro de Colegio Novohispano del siglo XVI. Estudio, edición crítica y notas. México: El Colegio de México, 2006.

Alonso Asenjo, Julio. «No se podía haser más: Relaciones de las fiestas por la canonización de Ignacio de Loyola y Francisco Javier en México (1622) y Puebla (1623)». TeatrEsco, 2 (2007). [Revista electrónica: http://parnaseo.uv.es/Ars/TEATRESCO/Revista/Revista2/ Relaciones_de_fiestas_en_Mexico_y_Puebla.pdf].

Alonso Asenjo, Julio. «Sobre el teatro humanísticoescolar del Ultramar hispánico». TeatrEsco, 3 (20082009). [Revista electrónica: http://parnaseo.uv.es/ Ars/TEATRESCO/Revista/Revista3/Sobre_el_teatro_humanistico-escolar_del_Ultramar_hispanico. pdf].

Alonso Asenjo, Julio. «Über das humanistische Schultheater der spanischen Überseegebiete». Christel Meier y Angelika Kemper (eds.). Europäische Schauplätze des Frühneuzeitlichen Theaters. Münster: Rhema, 2011: 335-368.

Alonso Asenjo, Julio. Teatro colegial colonial de jesuitas de México a Chile. Valencia: PUV-Parnaseo, 2012.

Alonso Asenjo, Julio. «Teatro musical en festejos escolares hispánicos de Edad Moderna». Rilce, 30.1 (2014): 19-43.

Arrom, José Juan, y José Manuel Rivas Sacconi, «La Láurea Crítica de Fernando Fernández de Valenzuela, primera obra teatral colombiana». Thesaurus. Boletin del Instituto Caro y Cuervo, 14 (1959): 161-185.

CARrancá, Raúl. La Universidad mexicana. México: FCE, 1969.

Carrasco Urgoiti, María Soledad. «La oralidad del vejamen de Academia». Edad de Oro, 7 (1988): 49-57.

Carreño, Alberto María. Efemérides de la Real y Pontificia Universidad de México según sus libros de claustros. 2 vols. México: UNAM, 1963.
Cervantes de Salazar, Francisco. México en 1554 y Túmulo Imperial. Ed. Edmundo O'Gorman. México: Porrúa, 1991.

Espinosa Pólit, Aurelio (S. I.). Los dos primeros poetas coloniales ecuatorianos, siglos XVII y XVIII: Antonio de Bastidas [y] Juan Bautista Aguirre. Quito, 1960: 219-223. [Accesible en: http://www.cervantesvirtual. com/obra/los-dos-primeros-poetas-coloniales-ecuatorianos-siglos-xvii-y-xviii-antonio-de-bastidas-y-juanbautista-aguirre--0/].

FARRÉ VIDAL, Judith. Dramaturgia y espectáculo del elogio: loas completas de Agustín de Salazar y Torres. 2 vols. Kassel: Reichenberger, 2003.

Forgues, Roland. Mujer, creación y problemas de identidad en América Latina / Femme, creátion et problèmes d'identité en Amérique Latine. Bogotá: Universidad de Los Andes, 1999.

Frost, Elsa Cecilia. Teatro mexicano. Historia y dramaturgia, V. Teatro profesional jesuita del siglo XVII. México: Consejo Nacional para la Cultura y las Artes, 1992.

Furlong, Guillermo (S. J.). Músicos argentinos durante la dominación española. Buenos Aires: Huarpes, 1945.

García Reidy, Alejandro. «Una aproximación al teatro de Juan López de Úbeda (Texto y contexto)». TeatrEsco, 3 (2008-2009). [Revista electrónica: http://parnaseo. uv.es/Ars/TEATRESCO/Revista/Revista3/Alejandro_ Garcia_Reidy-JuanLopezDeUbeda.pdf].

Góngora, Luis de. Sonetos completos. Ed. Biruté Ciplijauskaité. Madrid: Castalia, 1980.

ICAZA, Francisco A. «Cristóbal de Llerena y los orígenes del teatro en la América española». Revista de Filología Española, 8 (1921): 121-130. (Reeditado en Cedomil Goic, Historia y critica de la literatura hispanoamericana. Barcelona: Crítica, 1988, vol. I, 344-347. El texto del entremés está accesible en línea: http://www. cervantesvirtual.com/nd/ark:/59851/bmc4x557).

IRviNG, David. "Musical politics of empire: the loa in 18th-century Manila». Early Music, 32, 3 (2004): 384-402.

Jiménez Rueda, Julio. Historia jurídica de la Universidad de México. México: Facultad de Filosofía y Letras, 1955.

Juana Inés de la Cruz, Sor. Obras completas. Vol. 3. Ed. Alfonso Méndez Plancarte. México: Fondo de Cultura Económica, 1976, 2a ed.

LobATo, María Luisa. «Mojigangas parateatrales y teatrales en la corte de Carlos II (1681.1700)». Javier Huerta Calvo, Harm den Boer y Fermín Sierra Martínez (eds.). El teatro español a fines del siglo XVII. Historia, cultura y teatro en la España de Carlos II. Amsterdam: Rodopi, 1989: vol. II, 569-588. 
LuCiani, Frederick. "Fantasmas en el convento: una máscara en San Jerónimo (México, 1756)». Ignacio Arellano y José Antonio Rodríguez Garrido (eds.). El teatro en la Hispanoamérica colonial. Madrid: Iberoamericana-Vervuert, 2008: 259-273.

Madrigal, Luis I. (coord.). Historia de la Literatura Hispanoamericana. Época colonial. Madrid: Cátedra, 1982.

Madroñal, Abraham. "De grado y de gracias". Vejámenes universitarios del Siglo de Oro. Madrid: CSIC, 2005.

Maldonado Macías, Humberto. «El Encomio quinto de Juan de Cigorondo». Literatura Mexicana, 4.1 (1990): 181-194.

Maldonado Macías, Humberto. «Un temprano juguete teatral del padre Juan de Cigorondo escrito en Guadalajara (1595)». Hombres y Letras del Virreinato. Homenaje a Humberto Maldonado. México: UNAMInstituto de Investigaciones Filológicas, 1995: 173-189.

Mariscal Hay, Beatriz. Carta del Padre Pedro de Morales, de la Compañia de Jesús, para el muy Reverendo Padre Everardo Mercuriano (...). México: El Colegio de México, 2000.

Menéndez Peláez, Jesús. «Entremeses del teatro jesuítico». Archivum, 56 (2006): 495-570.

Mercado, Pedro de. Historia de la Provincia del Nuevo Reino y Quito de la Compañia de Jesús. Bogotá: Empresa Nacional de Publicaciones, 1957. [Accesible en http:// www.cervantesvirtual.com].

Monumenta Mexicana. VI (1596-1599). Félix Zubillaga (ed.). Romae: Institutum Historicum Societatis Iesu (Monumenta Historica Societatis Iesu, 114), 1976.

Omacini, Elena. "Un vejamen mexicano inédito del siglo XviII: la Huerta frutal del Br. Jacinto Martínez». Boletín del Instituto de Historia Argentina y Americana, 16 (1980): 581-617.

Omacini, Elena. "Teatro de los dioses, de Pedro José Sánchez Meza. Estudio preliminar, edición y notas». José M. Mariluz Urquijo, Elena Omacini y Daisy Rípodas Ardanaz, Tres estudios novohispanos. Sociedad. Letras. Artes. Buenos Aires: Libros de Hispanoamérica, 1983: 47-132.

Osorio Romero, Ignacio. «Un tocotín inédito del siglo xvII». Revista de Bellas Artes, 21 (1975): 9-16.

Osorio Romero, Ignacio. Colegios y profesores jesuitas que enseñaron latín en Nueva España (1572-1767). México: UNAM, 1979.

Padilla Zimbrón, Edith. «El tocotín como fuente de datos históricos». Destiempos. Dossier Virreinatos, 14.3 (2008): 235-249.

Partida Tayzan, Armando. "El Tocotín en la loa para el auto El Divino Narciso. ¿Criollismo sorjuanino?»
Cuadernos de Sor Juana, México: UNAM, 1995: 243271. [Accesible en http://www.cervantesvirtual.com]. Pascual Barea, Joaquín. «Neo-Latin Drama in Spain, Portugal and Latin America». Jan Bloemendal y Howard B. Norland (eds.). Neo-Latin Drama and Theatre in Early Modern Europe. Leiden-Boston: Brill, 2013: vol. III, 545-631.

Pasquariello, Anthony M. "The Evolution of the Loa in Spanish America»: Latin American Theatre Review, 3.2 (1970): 5-19.

Pérez de Ribas, Andrés. Triunfos de nuestra santa Fe (...). 3 vols. México: Layac, 1944.

Quiñones Melgoza, José. Teatro mexicano. Historia y dramaturgia, IV. Teatro escolar jesuita del siglo XVI. Estudio introductorio, traducción y notas. México: Consejo Nacional para la Cultura y las Artes, 1992.

Retana, Wenceslao E. Noticias histórico-bibliográficas del teatro en Filipinas, desde sus origenes hasta 1898. Madrid: Victoriano Suárez, 1910.

Rivas Sacconi, José Manuel. El latín en Colombia. Bosquejo histórico del humanismo colombiano. Bogotá, Instituto Caro y Cuervo, 1949.

Robles, Antonio de. Diario de sucesos notables (16651703). 3 vols. México: Porrúa, 1972.

Rubio MaÑé, Jorge Ignacio. El Virreinato IV. Obras públicas y educación universitaria. México: FCE, 1983.

SAINZ Bariáin, Isabel. «El “tocotín” en los fatos novohispanos: una muestra de sincretismo cultural». Miguel Zugasti (ed.). Teatro, fiesta y ritual en España y sus virreinatos americanos (siglos XVI-XVII). Número monográfico de Rilce, 32.3 (2016): 737-757.

Serna González, Francisco Javier. Social murder. Silent acts. Syncretism, Countersyncretism, Antesyncretism. Tesis doctoral. New York University: UMI-ProQuest LLC, 2008.

Summers, William J. «The Jesuits in Manila, 1581-1621: The Role of Music in Rite, Ritual, and Spectacle». John W. O'Malley et alii (eds.). The Jesuits II: Culture, Sciences, and the Arts, 1540-1773. Toronto: University of Toronto Press, 2006: 659-679.

Vargas Ugarte, Rubén. Manuscritos peruanos. Lima, 1940.

Zugasti, Miguel. «Loa». Diccionario de la comedia del Siglo de Oro. Frank P. Casa, Luciano García Lorenzo y Germán Vega García-Luengos (eds.). Madrid: Castalia, 2002: 198-199.

Zugasti, Miguel. «Aspectos sobre la loa y la música en el umbral de la fiesta barroca». E-Humanista. Journal of Iberian Studies, 6 (2006): 100-113. [Revista electrónica: http://www.ehumanista.ucsb.edu/sites/secure. lsit.ucsb.edu.span.d7_eh/files/sitefiles/ehumanista/ volume6/Zugasti.pdf]. 
